\title{
An investigation into the attitudes of academic librarians towards Internet plagiarism of HE students
}

\author{
Rebecca Bartlett, Biddy Casselden
}

\begin{abstract}
This paper investigates the attitudes of academic librarians towards Internet plagiarism by higher education students in the United Kingdom (UK), examining how they define Internet plagiarism, their perceived role in combating this phenomenon, and the skills and techniques they have or will adopt to achieve this. A Delphi study was undertaken using a sample of 10 respondents. The responses demonstrated that plagiarism is a multifaceted term and not easily definable, however respondents were unanimous in their opinion that the Internet has made it easier to plagiarise. The potential for active collaboration between librarians and academics to jointly address Internet plagiarism was seen as vital by all respondents, although opinion was divided on the role of librarians and academics. A blended approach is recommended, which involves involving policing and prevention; in addition to ensuring that students are achieving information literacy well before they reach the gates of the University.

\section{Introduction}

This research paper aims to report an investigation into the attitudes of academic librarians towards Internet plagiarism of higher education students in the United Kingdom (UK), particularly with regard to how they define Internet plagiarism, their perceived role in combating this phenomenon, and the skills and techniques they have or will adopt to achieve this.

The term 'plagiarism' can be traced back to the Latin word plagiarius meaning kidnapper or plunderer (Park, 2003; Granitz and Loewy, 2006; Sharkey and Culp, 2005). Baruchson-Arib and Yaari (2004) attest that since the eighteenth century
\end{abstract}

\section{Authors}

Rebecca Bartlett works as a Parliamentary Information Officer at the Scottish Parliament. She recently graduated from Northumbria University with a MA in Information and Library Management.

Biddy Casselden is a senior lecturer and programme leader of the MA/MSc Information and Library Management by Distance Learning programme at Northumbria University.

Email: b.casselden@northumbria.ac.uk 
the word has generally been associated with language and literary theft, consequently in a literary sense plagiarists "borrow, steal or take material belonging ostensibly to someone else" (Marsh, 2007,31). The longevity of plagiarism is recognised by Lampert $(2008,49)$ who is keen to point out that librarian involvement in plagiarism is not new, stating "reference librarians have probably helped track down plagiarised texts (...) for centuries."

The rapid growth of the Internet with its wealth, immediacy and universality of information has spawned a new form of plagiarism which has been labelled "cyberplagiarism" (Singh, 2005, 918), "cybercheating" (Stebelman, 1998, 48), "cut and paste plagiarism" (Granitz and Loewy, 2006, 297) and "e-plagiarism" (Sharkey and Culp, 2005), resulting in what Junion-Metz (2000) calls the eplagiarism plague. Research indicates the level of students admitting to committing Internet plagiarism varies, ranging from 15\% (Burke, 2004), $40 \%$ (Wood, 2004) 50\% (Szabo and Underwood, 2004) to as much as 80\% (Auer and Krupar, 2001; Gorman, 2006).

There is mixed debate as to the severity of this phenomenon, and if indeed it is a problem. Some authors are sceptical about the assertion that the Internet has increased plagiarism, for example, Scanlon and Neumann (2002) argue that the growth of the Internet has not led to an exponential rise in student plagiarism, and that levels of Internet plagiarism reflected levels of traditional plagiarism. Similarly, Selwyn (2008) reported that students were almost equally as likely to commit plagiarism from printed resources as they were from electronic resources. However, these views represent a minority opinion in the literature, with an alternative viewpoint offered by authors including (Gorman, 2008; Auer and Krupar, 2001; Lampert, 2008 and Smith, 2003) who all suggest student plagiarism has increased as a direct consequence of the Internet.

While studies exist reflecting on Internet plagiarism from the perspective of a student (for example Ashworth et al., 1997) and teaching staff (for example, Burke, 2004) there is little concerning librarian attitudes and the role they have to play in becoming, "plagiarism busters" (Wood 2004, 237). Not only are librarians are in a "unique position" to confront the problem (Lampert 2008, 145), they also have an "ethical obligation" to help tackle this phenomenon (Auer and Krupar 2001, 427). It is for this reason that this study concentrates on the attitude of the librarian towards this phenomenon, and what they can do to alleviate the problem.

\section{Methodology}

A Delphi study was undertaken in order to discover how academic librarians viewed student Internet plagiarism, how they viewed their role in terms of combating it, and opinions regarding expectations of their role expressed in the literature.

The Delphi method is sufficiently versatile to allow it to be applied to the exploration and resolution of issues in areas including health, education and the environment (Skulmoski et al. 2007). It has also been used in the field of librarianship (for example Westbrook (1997); Feret and Marcinek (2005). 
Pickard (2007) outlines the stages a traditional Delphi study should follow. These stages served to underpin the implementation of the research project and enabled a logical and organised study. The stages followed, as suggested by Pickard (2007), can be defined as to

- Determine the overall aim of the study

- Conduct a comprehensive review of literature relevant to the study

- Secure expert participants for the study

- Ensure participants are well informed of what will be expected of them as the study progresses

- Create a questionnaire for the first round of the Delphi study

- Pilot the questionnaire and amending as necessary

- First round - provide an opportunity for participants to complete the piloted questionnaire

- Analyse the first round responses; presented anonymously to participants

- Second round - provide an opportunity for respondents to review and reflect on the findings of the first round and provide further comment where necessary

- Repeat the process if necessary

- Present the findings of the study

An important consideration in any Delphi study is the selection of participants, particularly the selection of expert participants. Although it is sometimes difficult to clearly define what is meant by an expert, Ziglio $(1996,14)$ does however offer an insight into what constitutes an expert; and that an expert should possess, "knowledge and practical engagement with the issues under investigation." Therefore for the purposes of this research, expert participants comprised academic librarians who possessed knowledge and/or practical experience of teaching about plagiarism and the Internet.

A group of 10 participants, as recommended by Ziglio (1996), was selected which provided a study group of sufficient size to incorporate the necessary range of experience and expertise, balanced with the time available for the study.

Although it could be argued that the views of 10 participants cannot fully represent a wider view, the careful selection of key experts providing meaningful responses, and the opportunity for informed group judgments (Adler and Ziglio $1996,14)$ ensures that the results are of value to a wider audience.

The use of email as the only means of communication throughout the Delphi study enabled participants to come from a widely dispersed geographical area within the UK. Additional benefits of using email included its speed of reaching those on the Delphi panel and removal of stationery costs traditionally associated with sending letters (Geist, 2010).

The range of questions asked on the Delphi questionnaire was limited to 8 open questions, concerning: 
- Definitions of plagiarism

- The role the Internet has played in student plagiarism

- Where responsibility lies in terms of combating student plagiarism

- The role of the librarian

- What skills librarians possess that help to confront internet plagiarism

- The role of librarians in individual HE institutions - with examples

- Partnership working to tackle Internet Plagiarism

- Use of technology to tackle Internet Plagiarsim

Use of open questions enhanced this qualitative data further, allowing the Delphi panellists greater freedom and opportunities to express their "feelings, ideas, experiences, opinions, views, attitudes and perspectives" (Davies, 2007, 152), in line with the overall aim and objectives of the study.

A pilot exercise to test the reliability and validity of the Delphi questionnaire was conducted as suggested by Davies (2007) and Pickard (2007, 127) who defines the piloting stage as "almost certainly the single most important step" in the Delphi process. This not only helped to ensure the use of good quality questions (Geist 2010, Skulmoski et al. 2007, Davies 2007 and Oppenheim 1992), but also ensured that wording was scrutinised to avoid misinterpretation, thereby leading to ambiguous answers (Davies 2007). The pilot provided useful feedback on the layout, sequence, structure and length of the questions which was incorporated into the final questionnaire.

As it is well documented that a Delphi study can be a lengthy time commitment (Hsu and Sandford, 2007; Cape, 2004, Rieger, 1986), and to avoid possible "Delphi fatigue" (Linstone 2002) of participants undertaking this on a voluntary basis, it was decided to limit the study to two rounds. Research conducted by Skulmoski et al. (2007) on the use of the Delphi method in graduate research reported the majority of Delphi studies consisted of three rounds. However, Cape $(2004,37)$ suggests a "well-designed two round survey can still produce good results." Although the likelihood of reaching a consensus after two rounds was more uncertain, it was decided that the information obtained would be invaluable to the study nonetheless.

A good response rate, according to Mullen $(2003,41)$, should be a minimum of $70 \%$ in a Delphi study. This was encouraged by giving participants a two week turnaround for responses, and sending reminders after week one, which helped to secure a100\% response rate in both rounds of the Delphi study undertaken.

The benefits of using a Delphi study are numerous. They ensure anonymity of participants enabling expression of opinions which an individual may not feel confident in expressing publicly (Brown, 1968) and allow participants to revise their input from previous rounds without embarrassment (Rowe and Wright, 1999). They also negate the possibility of face to face confrontation which may occur in other methodologies, for example focus groups (Brown, 1968; Howze and Dalrymple, 2004; Westbrook, 1997; Rowe and Wright, 1999; Mullen, 2003). 
Dominance of certain characters is reduced through independent completion of the study (Brown, 1968; Westbrook, 1997; Mullen, 2003). Kochtanek and Hein $(1999,247)$ recognise a Delphi study allows all participants "equal opportunity and equal weight in their input." This is particularly useful for this subject where there is potential for differing views on how librarians can contribute towards combating Internet plagiarism.

A unique feature of the Delphi methodology is the provision of controlled feedback between rounds to respondents. Hsu and Sandford $(2007,2)$ outline the feedback process as consisting of a "well organised summary of the prior iteration [allowing] each participant an opportunity to generate additional insights and more thoroughly clarify the information developed by previous iteration." This period for reflection can be considered advantageous when comparing methods of qualitative research.

However, it would be foolish to assume any research methodology is without its limitations or criticisms. An early critic of the Delphi methodology was Sackman (1975) who vociferously attacked the methodology for failing to follow established scientific procedures however this was quickly refuted by Goldschmidt (1975). These limitations include the broad nature of questions (Kochtanek and Hein, 1999); the potential for researchers to over-analyse their findings (Westbrook, 1997); the lengthy time commitment required from participants (Pickard, 2007; Cape, 2004) the small sample size (Skulmoski et al., 2007) and the potential for responses to be influenced by personal agendas (Skulmoski et al., 2007).

However Geist (2010) is right to point out that such criticisms can be levelled at any poorly executed research methodology and are not unique to a Delphi study.

\section{Analysis}

Analysis of the data from this study was required to be structured and systematic in order to enable full understanding and interpretation of the data. As qualitative analysis requires a "deep and focussed interaction with the raw data" (Pickard, 2007, 242), the data was analysed using coding and classification; identifying categories, themes and patterns which emerged from the data. Also, use of content analysis, whereby labels were attached to "segments of data that depict what each segment is about" (Charmaz 2006, 3) enabled greater understanding of the data obtained.

\subsection{Definition of plagiarism}

All ten respondents agreed that plagiarism could be defined as taking other people's work and passing it off as one's own, original work. However when looking closer at what this means, respondent opinion was divided. The term "stealing knowledge" was used by one respondent in the first round, which caused disagreement amongst some of the respondents, who felt that the term "stealing" was too strong, and that the possibility that plagiarism could be unintentional rather than malicious had to be considered. The division of opinion between Delphi respondents reflects the divisions that exist within published literature as to whether "stealing" and "theft" are synonymous with plagiarism. 
For example, Granitz and Loewy (2006) conducted a study in which the majority of respondents (42\%) associated plagiarism with deontological philosophy. These authors take the uncompromising position that "under deontology, plagiarism is morally wrong; perpetrators are stealing" (Granitz and Loewy, 2006, 297). In opposition authors such as Bombaro (2007) state that accusing a student caught plagiarising of theft, is harsh.

Unintentional plagiarism was something that all respondents agreed could happen, due to a number of reasons including, "poor note taking, forgetting to include speech marks, incorrect referencing and an inability to correctly summarise or paraphrase", in addition, "poor handling of information " and "bad scholarship" were added to this list. The possibility that plagiarism may occur unintentionally is also emphasised in literature. Ashworth et al. $(1997,201)$ claim that there is "widespread ignorance concerning [plagiarism]" and that students are "unsure about precisely what [it is]."

A number of respondents supported the role of the librarian in alleviating accidental plagiarism through referencing education. Additional roles librarians could undertake to alleviate unintentional plagiarism included highlighting the consequences of plagiarism, advising and suggesting databases for students, and highlighting how to use information found on the Internet appropriately. The role of the librarian in advising and educating on plagiarism, and Internet plagiarism in particular, is a common theme expressed in the literature on this topic (Auer and Krupar, 2001; Wood, 2004; Lampert, 2004).

\subsection{The role of the Internet}

The ease with which Internet plagiarism can be carried out was a key theme to emerge in the first round of the Delphi study with all ten participants making reference to it. There was general agreement concerning the fact that the Internet afforded students with opportunities to "cut and paste" or "copy and paste" text or chunks of text from websites directly into their own assignments.

In addition respondents commented on the fact that the prevalence of "buy your essay" sites and paper mills had resulted in an increase in Internet plagiarism. This echoes the view expressed by Mundava and Chaudhuri $(2007,171)$ who state that the "proliferation of paper mills on the Internet is another factor enticing students to plagiarise." This view is also supported by, among others, Burke (2004) and Park (2003).

Respondents agreed that time pressures on students played a part in increasing plagiarism, in that students increasingly may need to undertake paid work to support their education, thereby reducing the amount of time they can commit to studying, and potentially increasing their temptation to copy from the Internet or buy web-produced assignments. Boden and Stubbings (2006) and Smith and Ridgway (2008) also support this view.

Respondents also suggested that students may lack adequate training on sourcing and using material on the Internet, with the consequence that "many students believe everything they see on the Internet and will often take sources at face value." The uncertainty surrounding correct referencing of Internet resources is 
acknowledged by Pears and Shields (2005) while Wiebe (2006) and Wood (2004) concede that difficulties exist for students who regard the Internet as a free for all, and have trouble understanding referencing procedures and requirements for its resources.

Opinion was divided amongst respondents concerning whether websites should contain information warning against the dangers of direct copying. Roughly half the respondents thought such guidance would not work in the real world, and students would simply ignore the warnings.

The majority of respondents felt that students were more likely to copy from the Internet than printed resources. They mentioned the ease of copying and pasting from the Internet compared to having to physically write or retype information from printed sources as the key factor in encouraging Internet plagiarism. Support for this argument is presented by Auer and Krupar $(2001,418)$ who declare "cutting and pasting from computer-based information using networked computers is easier than retyping material from a book."

\subsection{The role of the librarian and educators}

There was also broad agreement from respondents after round one that librarian involvement in plagiarism instruction is a "natural extension of [their] traditional role as gatekeepers of information" (Maxymuk 2006, 45). However there was caution as to the boundaries of such instruction, and opinion was divided as to whether such a role should be merely instructional or more involved. Roughly half of the respondents felt the role of educating students on using and referencing resources correctly, should not extend to policing and punishing plagiarists, thereby acting as "vehicles for the message".

Participants however were united in the view that students should take ultimate responsibility for ensuring their work avoided plagiarism, and that this responsibility followed the provision of plagiarism instruction/guidance from the academic institution. All respondents advocated a role for teaching staff in informing/advising/educating students on plagiarism, and its avoidance, alongside the teaching of correct referencing and citation procedures. The latter of which librarians had an important role to play.

Some respondents also placed emphasis on the role of teaching staff suggesting that plagiarism could, to a large extent, be "designed out" by teaching staff through their choice of assignment. Culwin and Lancaster (2001) encourage academics to change assignment criteria annually and to set unique and specific assignments requiring the personal reflections of students. This tactic is also supported by Szabo and Underwood (2004), Gourlay and Greig (2007); Granitz and Loewy (2006); Smith (2003) and Gajadhar (1998) while Maxymuk (2006) suggests including marked oral presentations in modules.

Participants were asked to consider what skills librarians have which could be used to ameliorate the problem of Internet plagiarism. The skills most readily identified were those of referencing and citation of sources.

All respondents agreed that a librarian's knowledge of referencing and citation procedures could be shared with students to help them avoid committing 
plagiarism. This view is supported by Bombaro $(2007,298)$ who declares that librarians are "experts in the areas of research and citing". In addition expert searching skills were seen as a key asset that librarians could use to enhance students' understanding of the Internet and their ability to source material effectively.

A suggestion to provide a list of high quality websites tailored to specific course needs, proposed by a respondent in round one, was opposed by other respondents on the grounds that it would not benefit the students, and would "stifle creative thought", discourage "independent thinkers" and dampen research skills and critical analysis of sources, in addition to creating extra work for librarians.

Several respondents identified librarian involvement in teaching about plagiarism and referencing, with one respondent detailing how they had been approached by a faculty to include plagiarism and the Internet in user sessions with students. There appears to be an increasing demand for academics to have Internet plagiarism guidance included in librarian-taught sessions. Respondents had also been involved in the production of booklets on "correct referencing and plagiarism avoidance" and offered online courses, presentations and workshops on these topics. This mirrors what published literature has detailed regarding how librarian-led plagiarism education can be delivered. These include disseminating information through "websites, tutorials and instructional material" (Wood, 2004, 240), workshops and seminars (Sharkey and Culp, 2005), web and paper based guidelines (Dames, 2007; Lampert (2008), online tutorials (Maxymuk, 2006) and classroom based teaching (Bombaro, 2007).

\subsection{The future}

Many respondents felt the involvement of librarians in plagiarism instruction would increase in the future. The proposition that librarians should be trained on plagiarism education received a mixed reaction from respondents. Although some felt continuing professional development (CPD) could only be a good thing, others were confident that their knowledge on the topic did not need further training.

As mentioned earlier, there was initially mixed views on the role of the librarian in combating plagiarism, especially regarding policing and punishment. There was a clearer consensus when considering the role of a librarian versus an academic. Here a clear distinction in what they saw as the appropriate role for librarians in this respect emerged. The majority of respondents considered that the role of the librarian should be limited to plagiarism education rather than detection. Some respondents expanded on this argument explaining that teachers were more familiar with the subject area and content of texts, and detection often involved "subject-specific knowledge" more suitable for teaching staff, whereas a librarian's role should be "limited to supporting the educational process on plagiarism." These sentiments reflect those expressed by among others Burke (2004) who writes in respect of the role of the librarian and plagiarism that "detection is not the main objective in a campaign against plagiarism" and Wood $(2004,240)$ who concludes that "it is more effective to prevent plagiarism than to spend time detecting it after it happens." 
An interesting finding from this study is that respondents welcomed this role as it enabled them to remain neutral in the eyes of the student. The importance of librarians remaining impartial is recognised by Buranen $(2009,30-31)$ who believes that they should be regarded by students as "not there to turn them in but to help them make sense of it all."

On the other hand, a few respondents argued that involvement in plagiarism detection may perhaps help to demonstrate the "value of information professionals within the institution".

All respondents agreed that in order to combat the problem of Internet plagiarism active cooperation between librarians and academic staff within academic institutions is vital. Similarly, this is identified in literature as a key alliance (Lampert, 2004; Mundava and Chaudhuri, 2007; Wiebe, 2006). A number of examples of this working relationship already in practice were identified by respondents, including joint teaching sessions and teaching materials, and helping academic staff to track down suspected Internet plagiarism

\subsection{Use of technology}

The use of technology such as Turnitin to tackle Internet plagiarism received a mixed response from respondents. A perceived benefit of such technology was that students could check and take responsibility for their own work through formative use of Turnitin however this view was countered by respondents who suggested that plagiarism had been a problem long before the introduction of the Internet. Failure of the technology could result in problems, and the additional time taken to check work using Turnitin was a negative association. The inability of such software to tackle the root cause and problems associated with plagiarism were also identified, and the more fundamental issue of trust, or lack of it, from compulsory use of such software - and the message this gives to students. Wiebe (2006) cautions that the introduction of Turnitin into an academic institution can result in a lack of trust between students and teachers. Among respondents, opinion was divided as to whether this was likely.

Half the respondents however, agreed that technology had some role to play in plagiarism detection but that it should be used alongside other more traditional methods such as education, as a blended approach.

\section{Conclusion}

The analysis of responses secured through the two rounds of the Delphi study have presented the views and experiences of current academic librarians towards Internet plagiarism and their significance in respect of published literature has been considered. Use of this Delphi approach enabled honest and open consideration of what can be a contentious subject for some. The fact that plagiarism is not strictly a 'black and white' topic meant that respondents were able to refine their thinking during the rounds, and consider fully the issues raised. The concluding part of this article will consider the key findings of this study and what it means for librarians, and future research that should be considered. 
- Definition of plagiarism - The responses concerning how one defines plagiarism demonstrated that plagiarism is a multifaceted term and not easily definable. However, agreement was reached that, at its most basic level, plagiarism could be defined as taking the work of others and presenting it as one's own work. The term 'stealing' was for some respondents too strong a term. However consensus was nevertheless secured on the potential for students to commit unintentional plagiarism with all participants recognising the potential for this, and suggesting ways in which it may occur.

- Role of the Internet - Respondents were unanimous in their opinion that the Internet has made it easier to plagiarise. Cut and paste plagiarism was a key theme for respondents.

- Roles and responsibilities of academic librarians - Opinion was divided concerning the roles and responsibilities of academic librarians in addressing and combating Internet plagiarism. It was viewed as a natural extension of a librarian's role, but there was disagreement on the extent of the role and whether this involvement should be limited to education rather than detection, and should include a policing and punishing aspect.

- Skills of the librarian - A number of relevant skills were identified that have been utilised by librarians to combat student levels of Internet plagiarism. The most frequently cited were the librarian's knowledge of correct referencing and citation procedures and their ability to find and use online information. This guidance was provided through a number of methods including taught sessions, workshops and online tutorials.

- Active collaboration between librarians and educators - The potential for active collaboration between librarians and academics to jointly address Internet plagiarism was seen as vital by all respondents. There was clear agreement on the distinction between their roles: librarians were viewed as plagiarism educators rather than detectors, in order to keep an air of neutrality. It was also suggested that Internet plagiarism education for students should begin at college "when students are first experiencing independent writing in producing coursework" therefore plagiarism education would become more of a role for college librarians. This is an interesting suggestion, particularly when viewed alongside the evidence from Williams (2010) who writes that schools and colleges are deploying plagiarism detection software "amid warnings that children as young as eleven need to be taught not to copy and paste from the Internet."

- Role of technology - The role of technology proved to be the most divisive in this Delphi study. An agreement could not be reached as to whether digital technology, particularly Turnitin, presented the most effective method to deter plagiarism or whether the introduction of technology could foster a lack of trust between students and academic institutions. However, respondents were in agreement that plagiarism software did not tackle the root of the problem of plagiarism, and that a blended approach was the key to tackling this phenomenon. 
Future research opportunities as a result of this study include examining the student perspective of plagiarism. Students are not a homogenous entity, however their views on what they perceive to be plagiarism, and how they search for information would help clarify the gap between professional and user perceptions and reality. Examining the views of those in the school/college sector would help to establish if this phenomenon is something that persists throughout the whole education system, and is not just an issue affecting those in higher education. It would also be helpful to conduct further research to determine whether the results of this study are out of tune with wider opinion or simply reflect the widely held differences of opinion towards this issue.

In conclusion, this study demonstrates that essentially a blended approach is necessary to tackle this problem, whereby policing and prevention are in force, offered by collaborative working with librarians and academics; in addition to ensuring that our students are achieving full information literacy well before they reach the hallowed gates of the University.

\section{References}

Adler, M. And Ziglio, E. (1996) Gazing into the oracle: The Delphi method and its application to social policy and public health. London: Jessica Kingsley Publishers.

Ashworth, P., Bannister., P and Thorne, P. (1997) Guilty in whose eyes?

University students' perceptions of cheating and plagiarism in academic work and assessment. Studies in Higher Education. 22(2), 187-203.

Auer, N and Krupar, E. (2001) Mouse Click Plagiarism: The role of technology in plagiarism and the librarian's role in combating it. Library Trends, 49(3), 415432.

Baruchson-Arbib, S and Yaari, E. (2004) printed versus internet plagiarism: a study of students' perception. International Journal of Information Ethics, 1, 1-7. URL: http://container.zkm.de/ijie/ijie/no001/ijie_001_05_baruchson.pdf [accessed: 08.8.10].

Boden, D and Stubbings, R. (2006) Re-writing the script: supporting academic integrity the library way! $2^{\text {nd }}$ Plagiarism Conference, Newcastle 19 June -21 June. Plagiarism advice.org. URL: http://www.plagiarismadvice.org/conference/previous-plagiarismconferences/2nd-plagiarism-conference-2006 [accessed: 8.8.10].

Bombaro, C. (2007) Using audiences response technology to teach academic integrity "The seven deadly sins of plagiarism" at Dickinson College. Reference Services Review. 35(2), 296-309.

Brown, B. (1968) Delphi process: a methodology used for the elicitation of opinions of experts. URL: http://www.rand.org/pubs/papers/2006/P3925.pdf [accessed: 17.8.10]. 
Buranen, L. (2009) A safe place: the role of librarians and writing centers in addressing citation practices and plagiarism. Knowledge Quest, 37(3), 24-33. American Association of School Librarians.

Burke, M. (2004) Deterring plagiarism: a new role for librarians. Library Philosophy and Practice, 6(2), 1-9. URL:

http://www.webpages.uidaho.edu/ mbolin/burke.htm [accessed: 08.8.11].

Cape, B. (2004) Gathering opinion and initiating debate: the success of the Delphi Method in purely qualitative research. Library and Information Research 28(89), 35-44.

Charmaz, K. (2006) Constructing grounded theory: a practical guide through qualitative analysis. London: SAGE Publications Ltd.

Culwin, F. and Lancaster, T. (2001) Plagiarism issues for higher education. VINE, 31(2), 36-41.

Dames, K. (2007) Understanding plagiarism and how it differs from copyright infringement. Computers in Libraries, 27(6), 24-27.

Davies, M. (2007) Doing a successful research project using qualitative or quantitative methods. Hampshire: Palgrave MacMillan.

Feret, B. And Marcinek, M. (2005) The future of the academic library and the academic librarian; a Delphi study reloaded. New Review of Information networking, 11(1), 37-63.

Gajadhar, J. (1998) Issues in plagiarism for the new millennium: an assessment odyssey. UltiBASE. URL: http://ultibase.rmit.edu.au/Articles/dec98/gajad1.htm [accessed: 08.8.11].

Geist, M. (2010) Using the Delphi method to engage stakeholders: A comparison of two studies. Evaluation and Programme Planning, 33(2), 147-154.

Goldschmidt, P. G. (1975) Scientific inquiry or political critique? Remarks on Delphi assessment, expert opinion, forecasting, and group process by $\mathrm{H}$. Sackman. Technological Forecasting and Social Change, 7, 195-213.

Gorman, G. (2008) The plague of plagiarism in an online world, Online Information Review, 32(3), 297-301.

Gourlay, L and Greig, J. (2007) Avoiding plagiarism, developing identities: responsibility, academic literacies and the curriculum. URL: http://www.plagiarismadvice.org/documents/gourlaygreig_casestudy.pdf [accessed: 07.8.10].

Granitz, N and Loewy, D. (2006) Applying Ethical Theories: Interpreting and Responding to Student Plagiarism. Journal of Business Ethics, 72(3), 293-306.

Howze, P and Dalrymple, C. (2004) Consensus without all the meetings: using the Delphi method to determine course content for library instruction. Reference Services Review, 32(2), 174-184. 
Hsu, C and Sandford, B. (2007) The Delphi technique: making sense of consensus. Practical Assessment, Research and Evaluation, 12(10), 1-8. URL: http://pareonline.net/pdf/v12n10.pdf [accessed: 08.8.11].

Kochtanek, K. and Hein, K. (1999) Delphi study of digital libraries. Information Processing and Management, 35(3), 245-254.

Lampert, L. (2008) Combating student plagiarism: an academic librarians guide. Oxford: Chandos Publishing Ltd.

Linstone, H. (2002) Eight basic pitfalls: a checklist. In: Linstone, H.A.and Turoff, M. (eds.) The Delphi Method: Techniques and Applications. Reading, MA:

Addison-Wesley. 559-571. URL: http://is.njit.edu/pubs/delphibook/ch8.pdf [accessed: 08.8.11].

Marsh, B. (2007) Plagiarism: alchemy and remedy in Higher Education. New York: State University of New York Press.

Maxymuk, J. (2006) The persistent plague of plagiarism. The Bottom Line: Managing Library Finances 19(1), 44-47.

Mullen, P. (2003) Delphi: myths and reality. Journal of Health Organization and Management, 17(1), 37-52.

Mundava, M and Chaudhuri, J. (2007) Understanding plagiarism. College and Research Library News, 68(3), 170-173. URL: http://crln.acrl.org/content/68/3/170.full.pdf+html [accessed: 08.8.11].

Oppenheim, A. (1992) Questionnaire design, interviewing and attitude measurement. London: Pinter Publications.

Park, C. (2003) In other (people's) words: plagiarism by university students literature and lessons. Assessment and Evaluation in Higher Education, 28(5), 471-488.

Pears, R and Shields, G. (2005) Cite them right: the essential guide to referencing and plagiarism. Newcastle upon Tyne: Pear Tree Books.

Pickard, A. (2007) Research methods in information. London: Facet Publishing.

Rieger, W. (1986) Directions in Delphi developments: dissertations and their quality. Technological Forecasting and Social Change 29(2), 195-204.

Rowe, G and Wright, G. (1999) The Delphi technique as a forecasting tool: issues and analysis. International Journal of Forecasting, 15(4), 353-375.

Sackman, H, (1975) Delphi critique: expert opinion, forecasting and group process. Lexington: DC Heath.

Scanlon, P and Neumann, D. (2002) Internet plagiarism among college students. Journal of College Student Development, 43(3), 374-485.

Selwyn, N. (2008) Not necessarily a bad thing...a study of online plagiarism amongst undergraduate students. Assessment and Evaluation in Higher Education, 33(5), 465-479.

Sharkey, J and Culp, F. (2005) Cyberplagiarism and the Library: Issues and Solutions, Reference Librarian, 44(91),103-115. 
Singh, S. (2005) Plagiarism: a librarians' view. Current Science, 89(6), 918. URL: http://www.ias.ac.in/currsci/sep252005/918.pdf [accessed: 08.8.10].

Skulmoski, G., Hartman, F. and Krahn, J. (2007) The delphi method for graduate research, Journal of Information Technology Education, 6, 1-21.

Smith, B. (2003) Fighting cyberplagiarism. Library Journal, 128(12), 22-23.

Smith, H. and Ridgway, J. (2008) Why students cheat (in their own words as well as those of others, $3^{\text {rd }}$ plagiarism conference. Newcastle 24-25 June. Plagiarism advice.org. URL: http://www.plagiarismadvice.org/conference/previousplagiarism-conferences/3rd-plagiarism-conference-2008 [accessed: 08.8.10].

Stebelman, S. (1998) Cybercheating: dishonesty goes digital, American Libraries, 29(8), 48-50.

Szabo, A and Underwood, J. (2004) Cybercheats: Is information and communication technology fuelling academic dishonesty? Active Learning in Higher Education, 5(2), 180-199.

Westbrook, L. (1997) information access issues for interdisciplinary scholars: results of a delphi study on women's studies research. Journal of Academic Librarianship, 23(3), 211-216.

Wiebe, T. (2006) College students, plagiarism and the internet: the role of academic librarians in delivering education and awareness. MLA forum, 5(2).

Williams, R. (2010) Cut and paste cheating from the internet rising in schools. The Guardian. 21 June.

Wood, G. (2004) Academic original sin: plagiarism, the internet and librarians. The Journal of Academic Librarianship, 30(3), 237-242.

Ziglio, E. (1996) The Delphi Method and its contribution to decision-making. In: Adler, M and Ziglio, E. (eds.) Gazing into the oracle: the Delphi Method and its application to social policy and public health. London: Jessica Kingsley Publishers.

\section{Open access and copyright}

Library and Information Research is an open access journal. A freely available copy of this paper may be downloaded from the journal's website: http://www.cilipjournals.org.uk/lir

Copyright and associated moral rights in works published in Library and Information Research are retained by the author(s) but this paper may be used freely, with proper attribution, in educational and other non-commercial settings. 